\title{
Safe and effective positioning of a left-sided double-lumen tube
}

\author{
Kurt Ruetzler, MD • Daniel I. Sessler, MD
}

Received: 23 July 2015/ Accepted: 5 August 2015/Published online: 1 September 2015

(C) Canadian Anesthesiologists' Society 2015

\section{To the Editor,}

As discussed in our paper, ${ }^{1}$ positioning the VivaSight DLT $34 \mathrm{sec}$ faster than positioning a conventional doublelumen tube is of marginal clinical importance. Then again, faster insertion is consistent with the fact that the tube is easy to use. Furthermore, the ability to obtain immediate assurance of at least an approximately correct position with the VivaSight camera likely facilitates initial insertion and awareness that the tube was not dislodged when changing the patient's position. Clinicians should nonetheless use flexible bronchoscopy to confirm the proper position of any double-lumen tube, and we recommended the procedure in our paper even for VivaSight tubes.

K. Ruetzler, MD ( $\square)$

Institute of Anesthesiology, University and University Hospital

Zurich, Zurich, Switzerland

e-mail: kurt.ruetzler@meduniwien.ac.at

K. Ruetzler, MD

Division of Cardiothoracic and Vascular Anaesthesia and Intensive Care Medicine, Medical University of Vienna, Vienna,

Austria

D. I. Sessler, MD

Department of Outcomes Research, Cleveland Clinic, Cleveland, $\mathrm{OH}$, USA
The most important clinical benefit of the VivaSight system appears to be continuous visualization of tube position during surgery, thus facilitating early detection of any intraoperative malpositioning.

Conflicts of interest None declared.

\section{Reference}

1. Schuepbach $R$, Grande $B$, Camen $G$, et al. Intubation with VivaSight or conventional left-sided double-lumen tubes: a randomized trial. Can J Anesth 2015; 62: 762-9. 